The standard treatment for Hamman's syndrome is clinical observation combined with supportive measures, usually in a hospital setting. The syndrome typically resolves spontaneously after two to seven days, and recurrence is uncommon ${ }^{(5)}$.

The prevalence of Hamman's syndrome is low. Nevertheless, it should be considered in the differential diagnosis of acute chest pain, especially in young patients with subcutaneous emphysema, and the possibility of pneumorrhachis should be investigated.

\section{REFERENCES}

1. Kelly S, Hughes S, Nixon S, et al. Spontaneous pneumomediastinum (Hamman's syndrome). The Surgeon. 2010;8:63-6.

2. Lopes FPL, Marchiori E, Zanetti G, et al. Spontaneous pneumomediastinum following vocal effort: a case report. Radiol Bras. 2010;43:137-9.

3. Murayama S, Gibo S. Spontaneous pneumomediastinum and Macklin effect: overview and appearance on computed tomography. World J Radiol. 2014;6:850-4.

4. Conti-de-Freitas LC, Mano JB, Ricz HMA, et al. A importância da suspeita clínica da síndrome de Hamman na sala de urgência. Rev Bras Cir Cabeça Pescoço. 2009;38:122-3.
5. Fatureto MC, Santos JPV, Goulart PEN, et al. Pneumomediastino espontâneo: asma. Rev Port Pneumol. 2008;14:437-41.

6. Alves GRT, Silva RVA, Corrêa JRM, et al. Pneumomediastino espontâneo (síndrome de Hamman). J Bras Pneumol. 2012;38:404-7.

7. Borem LMA, Stamoulis DNJ, Ramos AFM. A rare case of pneumorrhachis accompanying spontaneous pneumomediastinum. Radiol Bras. 2017;50:345-6.

8. Oertel MF, Korinth MC, Reinges MH, et al. Pathogenesis, diagnosis and management of pneumorrhachis. Eur Spine J. 2006;15 Suppl 5: $636-43$.

Andres Eduardo Cruz Guataqui ${ }^{1}$, Bernardo Carvalho Muniz ${ }^{2, a}$, Bruno Niemeyer de Freitas Ribeiro ${ }^{2, b}$, Luis Henrique Spielmann ${ }^{1}$, Miguel Angelo Milito ${ }^{1}$

1. Hospital Santa Teresa, Petrópolis, RJ, Brazil. 2. Instituto Estadual do Cérebro Paulo Niemeyer - Departamento de Radiologia, Rio de Janeiro, RJ, Brazil.

Correspondence: Dr. Bernardo Carvalho Muniz. Instituto Estadual do Cérebro Paulo Niemeyer - Departamento de Radiologia. Rua do Resende, 156, Centro. Rio de Janeiro, RJ, Brazil, 20231-092. Email: bernardocmuniz@yahoo.com.br.

a. https://orcid.org/0000-0003-1483-2759; b. https://orcid.org/0000-0002-1936-3026. Received 21 August 2017. Accepted after revision 22 September 2017.

http://dx.doi.org/10.1590/0100-3984.2017.0141

\title{
$(\infty)) \mathrm{EY}$
}

\section{Klippel-Feil syndrome accompanied by partial cleft of the cervical spine: a not-so-unusual combination?}

\section{Dear Editor,}

In this report, we present two cases within the spectrum of Klippel-Feil syndrome (KFS) accompanied by posterior partial split of the spinal cord. The first case involved a woman who underwent magnetic resonance imaging (MRI) of the cervical and thoracic spine to investigate the presence of hemivertebrae and scoliosis. The images showed fusion from C2 to C5, together with posterior spinal cord cerebrospinal fluid cleft (Figure 1). The second case involved an adolescent male hospitalized for cerebrospinal fluid shunt valve replacement and correction of hydrocephalus. MRI revealed extensive fusion and deformity of the vertebrae throughout the cervical segment and superior thoracic segment, accompanied by a long posterior cerebrospinal fluid cleft that extended from the medulla oblongata to the superior thoracic segment of the spinal cord (Figure 2).

KFS is characterized by congenital fusion of two or more vertebral bodies, of unknown cause. Etiological hypotheses include injury occurring at 3-8 weeks of gestation and an association with the genes that control the process of embryonic somite formation $^{(1)}$. The classic clinical triad, as described by Maurice Klippel and André Feil, consists of shortening of the neck, low posterior hairline, and limited range of motion of the neck, being present in only $50 \%$ of cases ${ }^{(2)}$. A wide range of brain and spinal cord malformations have been reported in patients with KFS. Diastematomyelia, one of the most widely reported malformations accompanying KFS, is characterized by complete division of the neural tube and the formation of two hemicords separated by osseocartilaginous septum, typically in the lower thoracic and lumbar regions ${ }^{(3)}$. Among the few reported cases of KFS, spinal cord alterations occur in up to $50 \%$, and posterior spinal cord cleft (also known as partial diastematomyelia) is one such alteration $^{(4-6)}$.

The relationship between vertebral fusion (KFS) and posterior partial spinal cord cleft is poorly documented and does not have a plausible origin like the defects involving the duplication of the notochord, which would explain in a more appropriate way the formation of diastematomyelia and the production of hemivertebrae or the so-called "butterfly" vertebrae ${ }^{(1)}$. One of the proposed mechanisms of vertebral fusion is extension of the cartilage formation process to the intervertebral disc material after completion of the primary segmentation (given that there
Figure 1. Case 1. A: Fusion of cervical vertebrae, extending from C2 to C5. B: Posterior division of the spinal cord.

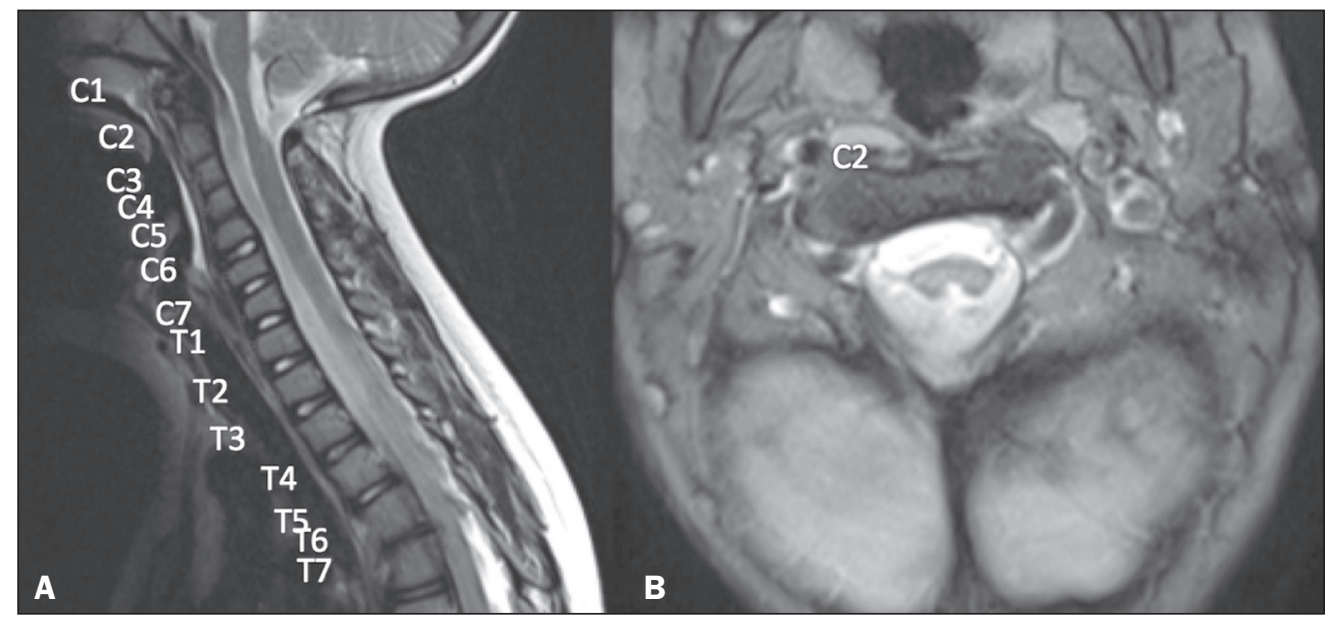




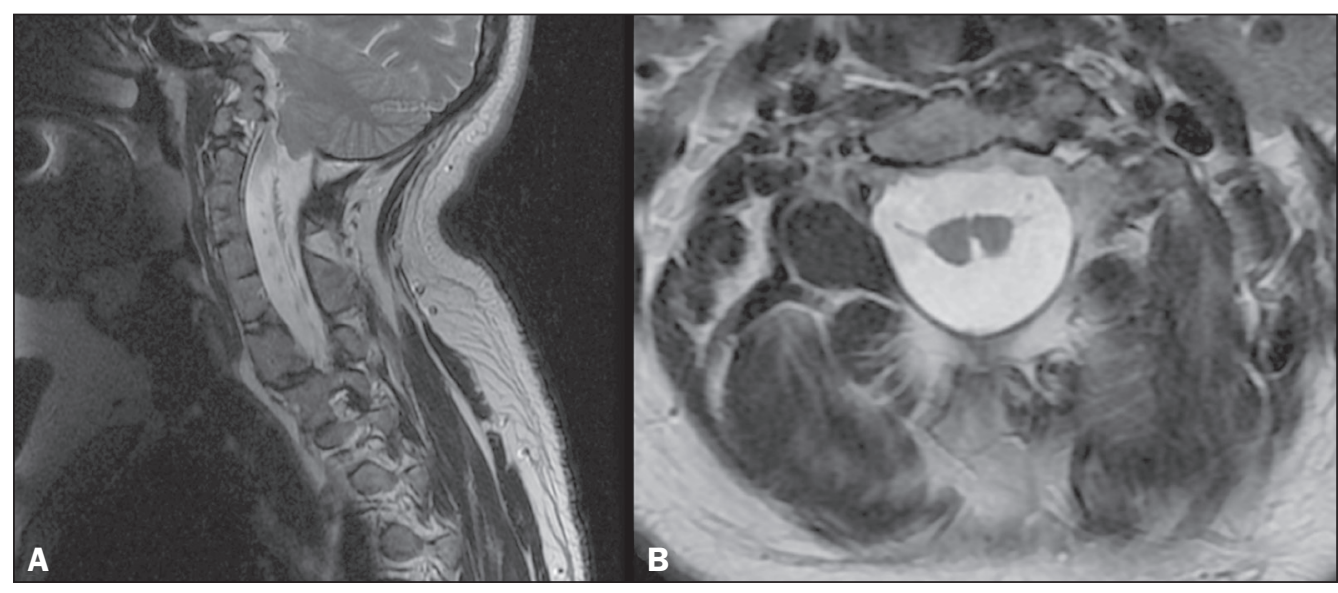

Figure 2. Case 2. A: Extensive fusion and deformity of the cervical vertebrae and the first thoracic vertebrae. B: Posterior split of the spinal cord, extending from the medulla oblongata to the first thoracic vertebrae. is no change in the number of nerve roots), culminating in the union of the vertebrae ${ }^{(1)}$. Spinal cord cleft has an even more obscure origin, and it has been suggested that it is due to focal injury with a superficial tissue repair process, although without repopulation with somite cells ${ }^{(1)}$.

In patients with KFS, spinal cord changes are considered to be one of the most important factors in the neurological deterioration process, second only to nerve involvement caused by degenerative spondylosis ${ }^{(4-6)}$. Because of the small number of cases reported, we raise the question about the actual prevalence of this combination and reiterate the need for active case finding, given that isolated KFS seems to be much more common in clinical practice than is the combination of KFS and spinal cord malformation, especially now that MRI has become much more accessible.

\section{REFERENCES}

1. David KM, Copp AJ, Stevens JM, et al. Split cervical spinal cord with Klippel-Feil syndrome: seven cases. Brain. 1996;1 19(Pt 6):1859-72.

2. Klippel M, Feil A. Un cas d'absence des vertèbres cervicales avec cage thoracique remontant jusqu'à la base du crâne. Nouvelle Iconographie de la Salpétrière. 1912;25:223-50.
3. Ulmer JL, Elster AD, Ginsberg LE, et al. Klippel-Feil syndrome: CT and MR of acquired and congenital abnormalities of cervical spine and cord. J Comput Assist Tomogr. 1993;17:215-24.

4. Royal S, Tubbs RS, D'Antonio MG, et al. Investigations into the association between cervicomedullary neuroschisis and mirror movements in patients with Klippel-Feil syndrome. AJNR Am J Neuroradiol. 2002;23:724-9.

5. Cochrane DD, Haslam RH, Myles ST. Cervical neuroschisis and meningocoele manque in type I (no neck) Klippel-Feil syndrome. Pediatr Neurosurg. 1990-1991;16:174-8.

6. Barkovich AJ. Pediatric neuroimaging. 4th ed. Philadelphia, PA: Lippincott Williams \& Wilkins; 2005.

\section{Vítor Lopes Galvão Vieira ${ }^{1, a}$, Debora Bertholdo ${ }^{1, b}$}

1. Hospital de Clínicas da Universidade Federal do Paraná (UFPR), Curitiba, PR, Brazil.

Correspondence: Dr. Vítor Lopes Galvão Vieira. Hospital das Clínicas - Universidade Federal do Paraná. Rua General Carneiro, 181, Alto da Glória. Curitiba, PR, Brazil. Email: vitorlgvieira@gmail.com.

a. https://orcid.org/0000-0002-4572-4315; b. https://orcid.org/0000-0002-4763-5631. Received 23 July 2017. Accepted after revision 19 October 2017.

http://dx.doi.org/10.1590/0100-3984.2017.0123

\section{$($ (c) $)$ EY}

\section{Cerebral amyloid angiopathy-related inflammation: findings on magnetic resonance imaging}

\section{Dear Editor,}

An 83-year-old female presented with a one-month history of daily non-pulsatile diffuse headaches that were refractory to analgesics, accompanied by discrete lower limb paresis. The patient also had systemic hypertension that was well controlled with medication. She reported no recent history of trauma, fever, or travel. A complete blood count showed no abnormalities, and the serology for HIV was negative, as was the VDRL test. Computed tomography (CT) of the skull showed diffuse hypodensity, predominantly in the white matter, making the sulci and fissures less prominent (Figure 1A). Magnetic resonance imaging (MRI) showed a hyperintense signal in T2-weighted and FLAIR sequences, without restricted diffusion, throughout the deep, periventricular white matter, predominantly in the frontal lobes, accompanied by multiple hypointense foci in a susceptibility-weighted imaging sequence, suggestive of microhemorrhages (Figures $1 \mathrm{~B}$ and $\mathrm{IC}$ ). In view of those findings, the working diagnosis was cerebral amyloid angiopathy-related inflammation (CAA-ri), which was later confirmed by biopsy. Pulse therapy with methylprednisolone was initiated, resulting in an improvement in the symptoms and in the imaging findings by two weeks after the start of the treatment (Figure 1D).

Recent studies in the radiology literature of Brazil have emphasized the importance of MRI for improving central nervous system diagnoses ${ }^{(1,2)}$. CAA-ri is a rare disease that typically affects patients between 60 and 80 years of age, with no predilection for either gender, manifesting clinically as a subacute cognitive decline, headache, convulsion, focal neurological deficits, and neuropsychiatric disorders ${ }^{(3-7)}$. The pathophysiology of CAA-ri is not well known. However, it is known that it consists in the pathological accumulation of beta-amyloid in the media and adventitia of small and medium cortical and leptomeningeal vessels, accompanied by a perivascular lymphocytic inflammatory process, although it remains unknown which process occurs first ${ }^{(3-7)}$.

On CT, the classical presentation of CAA-ri is unifocal cortical and subcortical hypodensity, predominantly in the parietal lobes; although diffuse involvement can occur, it is less common and is usually asymmetric ${ }^{(3-7)}$. On MRI, hyperintense signals without restricted diffusion (characteristic of vasogenic edema) 